\title{
A novel anthracene derivative, MHY412, induces apoptosis in doxorubicin-resistant MCF-7/Adr human breast cancer cells through cell cycle arrest and downregulation of P-glycoprotein expression
}

\author{
UMASANKAR DE ${ }^{1}$, PUSOON CHUN ${ }^{2}$, WAHN SOO $\mathrm{CHOI}^{3}$, BYUNG MU LEE $^{4}$, NAM DEUK KIM ${ }^{1}$, \\ HYUNG RYONG MOON ${ }^{1}$, JEE H. JUNG ${ }^{1}$ and HYUNG SIK KIM ${ }^{4}$ \\ ${ }^{1}$ College of Pharmacy, Pusan National University, Busan 609-735; ${ }^{2}$ College of Pharmacy, Inje University, \\ Gyeongnam 621-749; ${ }^{3}$ Institute of Biomedical Science and Technology, College of Medicine, Konkuk University, \\ Chungju 380-701; ${ }^{4}$ School of Pharmacy, Sungkyunkwan University, Suwon 440-746, Republic of Korea
}

Received August 30, 2013; Accepted October 14, 2013

DOI: $10.3892 /$ ijo.2013.2160

\begin{abstract}
New potential chemotherapeutic strategies are required to overcome multidrug resistance (MDR) in cancer. This study investigated the anticancer effect of a novel anthracene derivative MHY412 on doxorubicin-resistant human breast cancer (MCF-7/Adr) cells. We measured cell viability and the expression of apoptosis-related genes; in addition, the antitumor activity of MHY412 was confirmed using an in vivo tumor xenograft model. MHY412 significantly inhibited the proliferation of MCF-7/Adr and MCF-7 cells in a concentration-dependent manner. Notably, the half-maximal inhibitory concentration $\left(\mathrm{IC}_{50}\right)$ values of MHY412 in MCF-7/Adr $(0.15 \mu \mathrm{M})$ and MCF-7 $(0.26 \mu \mathrm{M})$ cells were lower than those of doxorubicin (MCF-7/ Adr, $13.6 \mu \mathrm{M}$ and MCF-7, $1.26 \mu \mathrm{M})$ after treatment for $48 \mathrm{~h}$. MHY412 at low concentrations induced $S$ phase arrest, but at high concentrations, the number of MCF-7/Adr cells in the sub-G1 phase significantly increased. MHY412-induced sub-G1 phase arrest was associated with inhibition of cyclin, cyclin-dependent kinase 2 (CDK2) and p21 expression in MCF-7/Adr cells. MHY412 markedly reduced P-glycoprotein (P-gp) expression and increased apoptotic cell death in MCF-7/Adr cells. Cleavage of poly-ADP ribose polymerase, reduced Bcl-2 expression, and increased in cytochrome $c$ release in MCF-7/Adr cells confirmed the above results. In addition, MHY412 markedly inhibited tumor growth in a tumor xenograft model of MCF-7/Adr cells. Our data suggest that MHY412 exerts antitumor effects by selectively modulating the genes related to cell cycle arrest
\end{abstract}

Correspondence to: Professor Hyung Sik Kim, School of Pharmacy, Sungkyunkwan University, San 30, Suwon, Gyeonggi-do 440-746, Republic of Korea

E-mail: hkims@skku.edu

Key words: MHY412, multidrug resistance, P-glycoprotein, breast cancer, apoptosis and apoptosis. In particular, MHY412 is a new candidate agent for the treatment of $\mathrm{Bcl}-2$ overexpressed doxorubicin-resistant human breast cancer.

\section{Introduction}

Breast cancer is the most commonly occurring cancer among women throughout the world, and over 39,000 women were expected to die from breast cancer in the USA in 2011 (1). In addition, breast cancer is one of the leading causes of cancer death among women of all races (2). Initially, chemotherapeutic drugs are effective against various types of human cancer, but eventually, the cells develop multidrug-resistant (MDR) (3). MDR is one of the major problems for successful cancer treatment. Several factors are responsible for broad-spectrum MDR. For example, overexpression of the membrane bound ATP-binding cassette transporters (ABC proteins) such as $\mathrm{P}$-glycoprotein (P-gp), breast cancer resistance proteins (BCRP), MDR-1 and MDR-2 normally prevent intercellular drug accumulation or modify the drug distribution in cancer cells (4-6). Previous studies indicated that MDR cancer cells exhibited different patterns of gene expression depending on drug treatment in cDNA microarray analysis. Especially, significant downregulation of apoptotic cell death-related genes and upregulation of cell cycle regulatory genes were observed $(7,8)$. In addition, P-gp inhibits apoptosis by preventing the release of cytochrome $c$ from the mitochondria; cytochrome $c$ is one of the key factors for apoptosis, which is mediated by the intrinsic mitochondrial pathway (9). A number of anticancer drugs show cytotoxic effects by interfering with the estrogen receptor (ER) expression in MDR breast cancer cell lines (10-12), but unfortunately, most of the resistant cancer cell lines have an ER-independent characteristic (13).

Doxorubicin (Dox) is widely used as a chemotherapeutic agent for breast cancer patients, but Dox cannot be used in some patients showing MDR. Dox is not effective in the Dox-resistant human breast cancer cell line MCF-7/Adr because of insufficient accumulation of the drug into the 


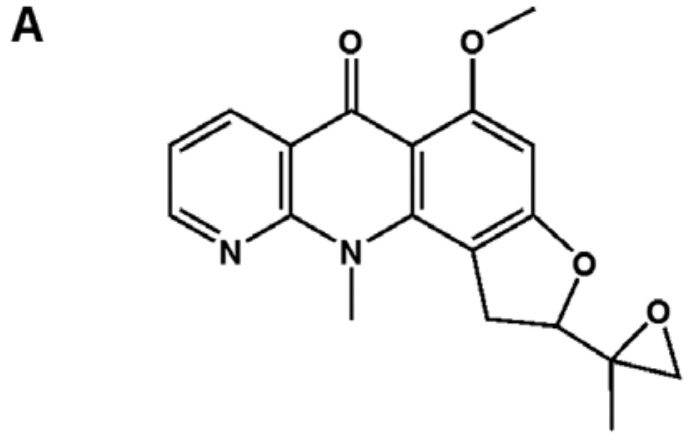

5-methoxy-11-methyl-2-(2-methyloxiran-2-yl)-1,2-dihydrobenz ofuro[4,5b] $[1,8]$ naphthyridin-6(11H)-one

MHY412<smiles>COc1cccc2c1C(=O)c1c(O)c3c(c(O)c1C2=O)C[C@@](O)(C(=O)CO)C[C@@H]3OC1CC(N)C(O)C(C)C1(C)O</smiles>

Doxorubicin

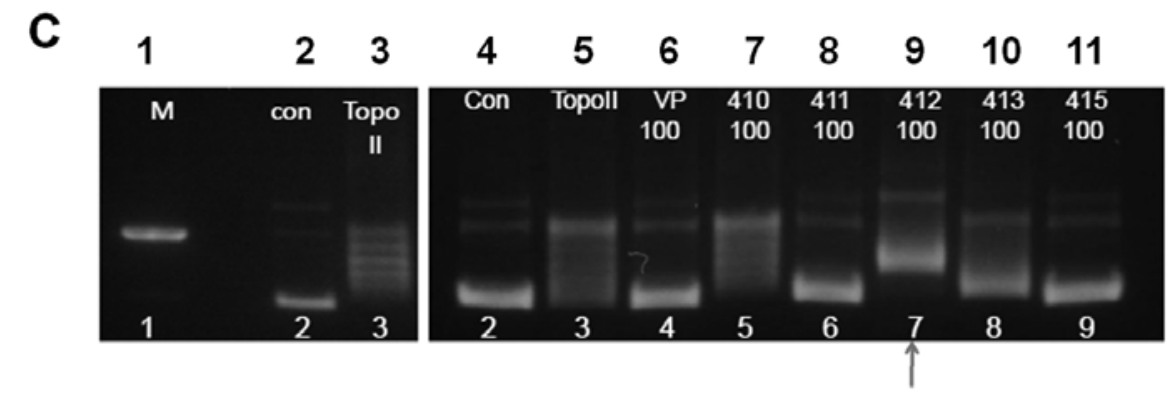

Figure 1. Chemical structures of (A) MHY412 and (B) doxorubicin. (C) Effect of MHY412 on topoisomerase II-mediated DNA relaxation. A DNA relaxation assay. Lane 1, marker; lane 2, only DNA; lane 3, DNA with topoisomerase II; lane 4, only DNA; lane 5, DNA and topoisomerase II; lane 6, DNA, topoisomerase II and $100 \mu \mathrm{M}$ etoposide; lanes 7-11, DNA, topoisomerase II and drugs $(100 \mu \mathrm{M})$.

cells by ABC transporters (14). Several antiapoptotic proteins prevent the induction of apoptosis in cancer cells. Bcl-2 is one such protein that protects the cells from apoptosis (15). This protein prevents opening of the mitochondrial permeability transition pores and significantly inhibits mitochondrial membrane depolarization and the release of apoptogenic factors to the cytosol $(16,17)$. A previous study showed that compared to MCF-7/Adr cells, MCF-7 cells have a higher level of Bcl-2 expression, suggesting that low sensitivity of MCF-7 apoptosis against lauryl gallate might be involved with Bcl-2 expression (18).

Many novel anthracene derivatives are synthesized to overcome MDR (19-21). Previous studies have shown that the cytotoxic effect of the novel anthracene derivative, HL-37, is significantly low in drug-resistant cancer cells. Furthermore, the anticancer activity of HL-37 in K562/Dox cells was stronger than that of the novel daunorubicin analogue 3-azidodaunorubicin $(21,22)$. Although Dox is effective in breast cancer cell lines (MCF-7 and MDA-MB-231), it has several limitations in that it is not effective against MDR cell line (MCF-7/Adr), and it is necessary to overcome these limitations. Therefore, we used the newly synthesized anthracene derivative MHY412 (Fig. 1A). Previously, we measured the inhibitory effects of MHY412 on the catalytic activity of topoisomerase II using topoisomerase II relaxation assays. MHY412 markedly inhibited the activity of the enzyme topoisomerase II (Fig. 1C). These data showed that MHY412 effectively inhibited the relaxation activity of topoisomerase II in a manner similar to that of etoposide.

The main purpose of our study was to investigate the anticancer potential of MHY412 in Dox-resistant MCF-7/Adr cancer cells, and we examined the molecular mechanism underlying the apoptotic cell death pathway induced by MHY412. Our study indicated that compared to Dox, MHY412 is a more effective anticancer agent; in addition, MHY412 is highly effective in MCF-7/Adr cells.

\section{Materials and methods}

Reagents. The novel compound MHY412 was provided by Professor Hyung Ryong Moon (Laboratory of Medicinal Synthetic Organic Chemistry, College of Pharmacy, Pusan National University, Korea). The reference compound (Dox, Fig. 1B) was purchased from Sigma-Aldrich Biotechnology (St. Louis, MO, USA). Culture medium and fetal bovine serum (FBS) were purchased from Gibco Invitrogen Corporation (Carlsbad, CA, USA). The primary antibodies for poly-ADP-ribose polymerase (PARP), Bax, Bcl-2, estrogen receptor $\alpha(E R \alpha)$, cyclin-dependent kinase 2 (CDK2), p21, cyclin D1, cyclin E1 and horseradish peroxidase-conjugated secondary antibodies were purchased from Santa Cruz Biotechnology (Santa Cruz, CA, USA). Annexin V-FITC apoptosis detection kit I was from BD Biosciences (San Diego, CA, USA). All other chemicals were purchased from Sigma- 
Aldrich. MHY412 was dissolved in dimethyl sulfoxide (DMSO) and stored at $-20^{\circ} \mathrm{C}$ until use. These agents were diluted to appropriate concentrations with culture medium containing $1 \% \mathrm{FBS}$. The final concentration of DMSO was less than $0.1 \%$ $(\mathrm{v} / \mathrm{v})$, which was also present in the corresponding controls.

Topoisomerase II-mediated DNA cleavage assay. To assess the effect of MHY412 on topoisomerase II, $0.25 \mu \mathrm{g}$ of supercoiled pHOT1 DNA was incubated with topoisomerase II enzymes at $37^{\circ} \mathrm{C}$ for $40 \mathrm{~min}$ in the presence or absence of MHY412. The DNA products were separately electrophoresed on agarose gels with or without ethidium bromide.

Cell culture. Human breast cancer MCF-7 cells were purchased from American Type Culture Collection (Manassas, VA, USA). MCF-7/Adr cells were kindly provided by Professor Kang Keun Wook (Seoul National University, Seoul, Korea). The cells were grown in Dulbecco's modified Eagle's medium (Gibco, Rockville, MD, USA) containing 10\% heat-inactivated FBS, $1.25 \mathrm{mM}$ HEPES and $100 \mathrm{U} / \mathrm{ml}$ penicillin/streptomycin. The cells were maintained as monolayers in a humidified atmosphere containing $5 \% \mathrm{CO}_{2}$ at $37^{\circ} \mathrm{C}$, and the culture medium was replaced every 2 days. After incubation for $48 \mathrm{~h}$, the culture medium was replaced with treatment medium containing the desired concentrations of chemicals.

Cytotoxicity assay. Cell viability was determined using 3-(4,5-dimethylthiazol-2-yl)-2,5-diphenyltetrazolium bromide (MTT; $5 \mathrm{mg} / \mathrm{ml}$, Sigma). The cultures were initiated in 96-well plates at a density of $2.5 \times 10^{3}$ cells per well. After incubation for $48 \mathrm{~h}$, the cells were treated with various concentrations of MHY412 and Dox (5 $\mu \mathrm{M})$ and were cultured for 24 and $48 \mathrm{~h}$, respectively. At the end of the treatment period, $15 \mu \mathrm{l}$ of MTT reagent was added to each well, and the cells were incubated for $4 \mathrm{~h}$ at $37^{\circ} \mathrm{C}$ in the dark. After incubation, the supernatant was aspirated, and formazan crystals formed were dissolved in $100 \mu \mathrm{l}$ of DMSO at $37^{\circ} \mathrm{C}$ for $10 \mathrm{~min}$ with gentle agitation. The absorbance per well was measured at $540 \mathrm{~nm}$ using the VERSA Max Microplate Reader (Molecular Devices Corp., Sunnyvale, CA, USA). Data was analyzed from 3 independent experiments and then was normalized to the absorbance of wells containing media only (0\%) and untreated cells (100\%).

Cell proliferation assay. MCF-7/Adr cells were treated with MHY412 $(0.05,0.1$ or $0.2 \mu \mathrm{M})$ or Dox $(5 \mu \mathrm{M})$. After $12 \mathrm{~h}$, the medium was removed and fresh medium was added; $12 \mathrm{~h}$ after the addition of the fresh medium, living cells were collected and counted using a cell counter. The counting process continued for 24 and $48 \mathrm{~h}$.

Western blot analysis. MCF-7 and MCF-7/Adr cells were treated with MHY412 $(0.05,0.1,0.2$ and $0.5 \mu \mathrm{M})$ or Dox $(5 \mu \mathrm{M})$ for $48 \mathrm{~h}$. The cells were harvested by trypsinization and were washed twice with cold phosphate-buffered saline (PBS). For total protein isolation, the cells were suspended in PRO-PREPTM protein extract solution (Intron, Seongnam, Korea), and protein concentrations were measured using a protein assay kit (Bio-Rad, Hercules, CA, USA) according to the manufacturer's instructions. Equivalent amounts of proteins were resolved and subjected to sodium dodecyl sulfate-polyacrylamide gel electrophoresis (SDS-PAGE) on $8-15 \%$ gels. After electrophoresis, the gels were transferred to polyvinylidene difluoride (PVDF) membranes (Millipore, Billerica, MA, USA), and the membranes were blocked with blocking buffer (TNA buffer containing 5\% skim milk) for $1 \mathrm{~h}$. Then, the membranes were incubated with various kinds of primary antibodies at $4^{\circ} \mathrm{C}$ overnight. After washing with TNA buffer (10 mM Tris- $\mathrm{HCl}, \mathrm{pH} 7.6 ; 100 \mathrm{mM} \mathrm{NaCl}$; and $0.5 \%$ Tween-20) for $1 \mathrm{~h}$, the membranes were incubated with horseradish peroxidase-conjugated anti-mouse $(1: 10,000)$ or anti-rabbit antibody $(1: 5,000)$ for $30 \mathrm{~min}$ at room temperature and then washed for $1 \mathrm{~h}$ with TNA buffer. The blots were developed using an enhanced chemiluminescence (ECL)-plus kit (Amersham Biosciences, Buckinghamshire, UK).

Flow cytometry analysis. The cells were treated with various concentrations of MHY412 (0.05, 0.1, 0.2 and $0.5 \mu \mathrm{M})$ or Dox $(5 \mu \mathrm{M})$ for $48 \mathrm{~h}$. The total number of cells, both in suspension and those adhered to the walls, for sub-G1 phase, and only those adhered to the walls for other cell cycle phases were harvested separately and washed in $1 \%$ bovine serum albumin (BSA) before fixing in $95 \%$ ice-cold ethanol containing $0.5 \%$ Tween-20 for $1 \mathrm{~h}$ at $-20^{\circ} \mathrm{C}$. The cells $\left(1 \times 10^{6}\right)$ were washed in $1 \%$ BSA, stained with cold propidium iodide (PI) staining solution $(10 \mu \mathrm{g} / \mathrm{ml}$ PI and $100 \mu \mathrm{g} / \mathrm{ml}$ RNase in PBS), and incubated in dark for $30 \mathrm{~min}$ at room temperature. Data acquisition and analysis was performed using a flow cytometry (Becton-Dickinson, San Jose, CA, USA).

Annexin V/PI binding assay. Annexin V/PI binding assay was performed according to manufacturer's instructions using the Annexin V-FITC detection kit I. The cells were treated with MHY412 $(0.05,0.1,0.2$ and $0.5 \mu \mathrm{M})$ or Dox $(5 \mu \mathrm{M})$ for $48 \mathrm{~h}$. The total number of cells were counted by trypsinization and washed twice with cold PBS. The cell pellet was resuspended with $100 \mu \mathrm{l}$ binding buffer at a density of $1 \times 10^{5}$ cells $/ \mathrm{ml}$ and incubated with $5 \mu \mathrm{l}$ of FITC-conjugated Annexin V and $5 \mu \mathrm{l}$ of PI for $15 \mathrm{~min}$ at room temperature in the dark. We added $400 \mu \mathrm{l}$ of binding buffer to each sample tube, and the samples were immediately analyzed using flow cytometry (Becton-Dickinson).

RNA extraction and RT-PCR analysis. The MCF-7/Adr cells were treated with MHY412 $(0.05,0.1$ and $0.2 \mu \mathrm{M})$ or Dox $(5 \mu \mathrm{M})$ for $48 \mathrm{~h}$. Total RNA was extracted using TRIzol reagent (Gibco) according to the manufacturer's protocol. cDNA was synthesized using a reverse transcription (RT) method. Briefly, $2 \mu \mathrm{g}$ of the total RNA was reverse transcribed for $50 \mathrm{~min}$ at $42^{\circ} \mathrm{C}$ in a $20 \mu \mathrm{l}$ reaction mixture containing $1 \mu \mathrm{l}$ of the oligo primer $(0.5 \mu \mathrm{g}), 10 \mathrm{mM}$ of the deoxy-NTP mixture, $25 \mathrm{mM}$ $\mathrm{MgCl}_{2}(4 \mu \mathrm{l}), 0.1 \mathrm{M}$ DTT $(2 \mu \mathrm{l})$, RNase Out Inhibitor $(1 \mu \mathrm{l})$, superscript II (50 units), and 10X RT buffer ( $2 \mu \mathrm{l})$ followed by denaturation at $70^{\circ} \mathrm{C}$ for $15 \mathrm{~min}$. The RT-synthesized cDNAs were further polymerase chain reaction (PCR)-amplified using the specific primers (Table I). cDNA $(2.0 \mu \mathrm{g})$ was amplified in a $25 \mu \mathrm{l}$ reaction mix containing a 10X PCR buffer $(2.5 \mu \mathrm{l})$, $50 \mathrm{mM} \mathrm{MgCl} 2(0.75 \mu \mathrm{l}), 10 \mathrm{mM}$ dNTP mix $(0.5 \mu \mathrm{l}), 20 \mu \mathrm{M}$ of each primer I $(0.25 \mu \mathrm{l})$ and primer II $(0.25 \mu \mathrm{l})$. The reaction was initiated at $94^{\circ} \mathrm{C}$ for $5 \mathrm{~min}$. Then, PCR was performed using a variable number of the following amplification cycles: dena- 
Table I. Primer sequences used in PCR amplification.

\begin{tabular}{ll}
\hline Gene & \multicolumn{1}{c}{ Sequence } \\
\hline P-gp & S: 5'-CCCATCATTGCAATAGCAGG-3' \\
& A: 5'-GTTCAAACTTCTGCTCCTGA-3' \\
BCRP & S: 5'-TGCCCAGGACTCAATGCAACAG-3' \\
& A: 5'-ACAATTTCAGGTAGGCAATTGTG-3' \\
GAPDH & S: 5'-GGCGTCTTCACCACCATGGAG-3' \\
& A: 5'-GCCTGCTTCACCACCTTCTTG-3'
\end{tabular}

S, sense; A, antisense.

turation at $94^{\circ} \mathrm{C}$ for $45 \mathrm{sec}$, annealing at $55^{\circ} \mathrm{C}$ for $45 \mathrm{sec}$, and extension at $72^{\circ} \mathrm{C}$ for $45 \mathrm{sec}$. The number of PCR cycles was estimated by a preliminary study to optimize the exponential phase of PCR. In addition, a final extension cycle of $72^{\circ} \mathrm{C}$ for 5 min was included. A $20 \mu \mathrm{l}$ aliquot of each PCR product was analyzed by gel electrophoresis on a $2 \%$ agarose $(w / v)$ gel. The molecular sizes of the amplified products were determined by comparing their sizes with those of the molecular weight markers (100 bp DNA ladder, Intron) run in parallel with the RT-PCR products.

Tumor xenograft model using nude mice. A tumor xenograft model was established using 6-week-old female BALB/c nude mice (Charles River Lab. Inc., Wilmington, MA, USA). Mice were housed and maintained in a pathogen-free facility under controlled temperature $\left(22 \pm 2^{\circ} \mathrm{C}\right)$ and lighting $(12 \mathrm{~h}$ light and dark cycles). All experimental procedures and protocols were approved by the Experimental Animal Care Commission of Pusan National University. Mice were injected subcutaneously into the right flank with $1.5 \times 10^{7}$ MCF-7/Adr cells suspended with $0.1 \mathrm{ml}$ serum-free media containing 50\% Matrigel. After inoculation and development of tumor, mice were randomized to 3 groups $(\mathrm{n}=6)$. MHY412 $(5 \mathrm{mg} / \mathrm{kg})$ and Dox $(5 \mathrm{mg} / \mathrm{kg})$ were administered intraperitoneally (i.p.) once a week to mice for 21 days, and control mice were administered with vehicle (DPBS) in a similar manner. For the duration of the experiment, the mice were observed for clinical signs, changes in body weight and possible side-effects of the administered drugs. Tumor sizes were measured 2 times in a week using calipers, and tumor volumes were calculated using a standard formula (width ${ }^{2} \mathrm{x}$ length $\mathrm{x} 0.052$ ). The mice were sacrificed by $\mathrm{CO}_{2}$ inhalation after 21 days, and tumor size and weight were recorded. The excised tumor tissue was fixed with $10 \%$ neutral formalin, and tissue sections were embedded with paraffin for histological analysis. The tumor sections were stained with hematoxylin and eosin (H\&E) and were viewed under an optical microscope (magnification, x200; Axiovert 200; Zeiss Inc., Göttingen, Germany). The images were recorded by a digital camera (Olympus Optical Co. Ltd., Tokyo, Japan).

Immunohistochemistry. Paraffin-embedded tissues were used to identify the proliferating cell nuclear antigen (PCNA). Deparaffinization was achieved with xylene followed by a descending series of ethanol concentrations. Antigen retrieval was performed in a microwave-heated citrate buffer $(\mathrm{pH}$ 6.0) for $20 \mathrm{~min}$. The endogenous peroxidases were blocked with $3 \% \mathrm{H}_{2} \mathrm{O}_{2} /$ methanol for $15 \mathrm{~min}$ at room temperature. The non-specific epitopes were blocked with $1 \%$ normal goat serum for $30 \mathrm{~min}$ at room temperature. The tumor sections were incubated overnight at $4^{\circ} \mathrm{C}$ with PCNA (1:100, Lab Vision Corporation, Fremont, CA, USA) antibodies. The tumor sections were counterstained with $\mathrm{H} \& \mathrm{E}$ to visualize the nuclei. The immunostained sections were viewed under an optical microscope (magnification, x200, Axiovert 200; Zeiss Inc.), and the images were recorded on a digital camera (Olympus Optical Co. Ltd.).

TUNEL assay. The level of apoptosis was determined using an ApopTag in situ apoptosis detection kit (Chemicon International, Temecula, CA, USA) according to the manufacturer's protocol. To determine terminal deoxynucleotidyl transferase-mediated dUDP nick-end labeling (TUNEL) expression in tissue sections, the number of apoptotic events was counted in 10 random fields by confocal laser scanning microscopy (Olympus FV10i, Olympus Optical Co. Ltd.) at a x400 magnification and that number was divided by the total number of cells per field.

Data analysis. All values are expressed as mean \pm standard error of mean (SEM) of at least 3 individual experiments. The statistical comparisons between the groups were performed using one-way analysis of the variance (ANOVA), and the threshold of the significance was calculated using Bonferroni's test. Statistical significance was set at $\mathrm{p}<0.05$.

\section{Results}

MHY412 suppresses the growth of breast cancer cells. The cytotoxicity of MHY412 in 2 types of breast cancer cells was assessed by using the MTT assay. The $\mathrm{IC}_{50}$ values of MHY412 and Dox against MCF-7/Adr and MCF-7 cells are shown in Fig. 2. MHY412 significantly reduced the growth of MCF-7 and MCF-7/Adr cells in a concentration-dependent manner. The cytotoxic potency of MHY412 was higher than Dox to both cell lines. The $\mathrm{IC}_{50}$ values of MHY412 in MCF-7/Adr $(0.15 \mu \mathrm{M})$ and MCF-7 $(0.26 \mu \mathrm{M})$ were lower than those of Dox in MCF-7/ $\operatorname{Adr}(13.6 \mu \mathrm{M})$ and MCF-7 $(1.26 \mu \mathrm{M})$ cells. The cytotoxicity of MHY412 was greater in MCF-7/Adr cells than in MCF-7 cells. In addition, we assessed the cell proliferation using a cell counting assay. MHY412 showed a significant decrease in cell number at low concentrations (Fig. 2C). Prominent morphological changes including cytoplasmic enlargement and cellular flattening were observed in the MCF-7/Adr cells after MHY412 treatment (Fig. 2D).

Effects of MHY412 on cell cycle regulation. To confirm the hypothesis that MHY412 can induce cell cycle arrest in MCF-7 and MCF-7/Adr cells, we performed DNA flow cytometry analyses. The cells were treated with MHY412 (0.05, 0.1, 0.2 and $0.5 \mu \mathrm{M})$ and Dox $(5 \mu \mathrm{M})$ for $48 \mathrm{~h}$, and the levels of cell cycle progression were monitored by flow cytometry. MHY412 significantly increased the number of MCF-7 cells in G1 phase arrest (Fig. 3A). In contrast, MHY412 markedly increased the population of cells in the $\mathrm{S}$ phase in MCF-7/Adr cells, and 


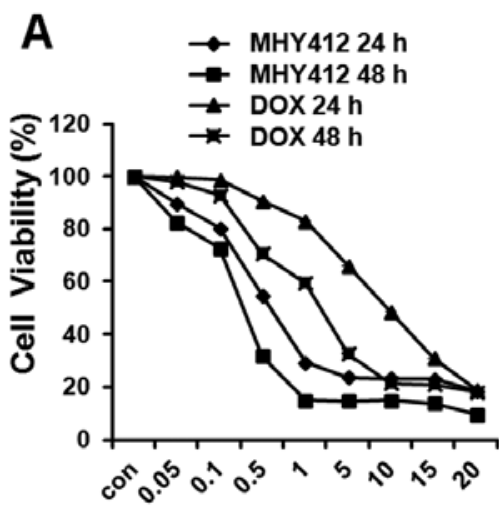

Concentrations $(\mu \mathrm{M})$

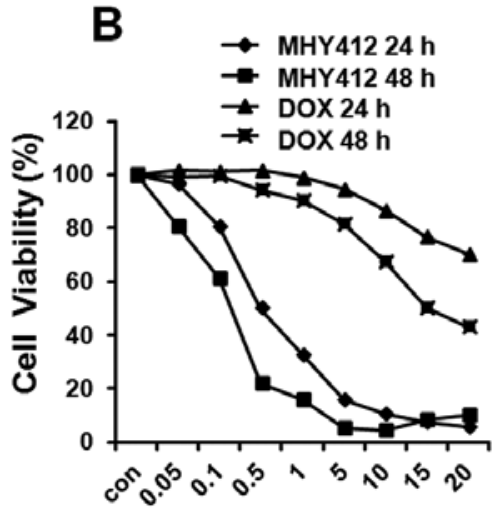

Concentrations $(\mu \mathrm{M})$

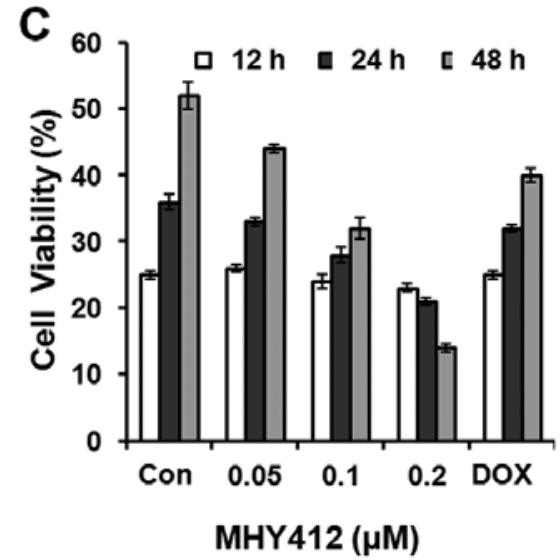

MHY412 ( $\mu \mathrm{M})$

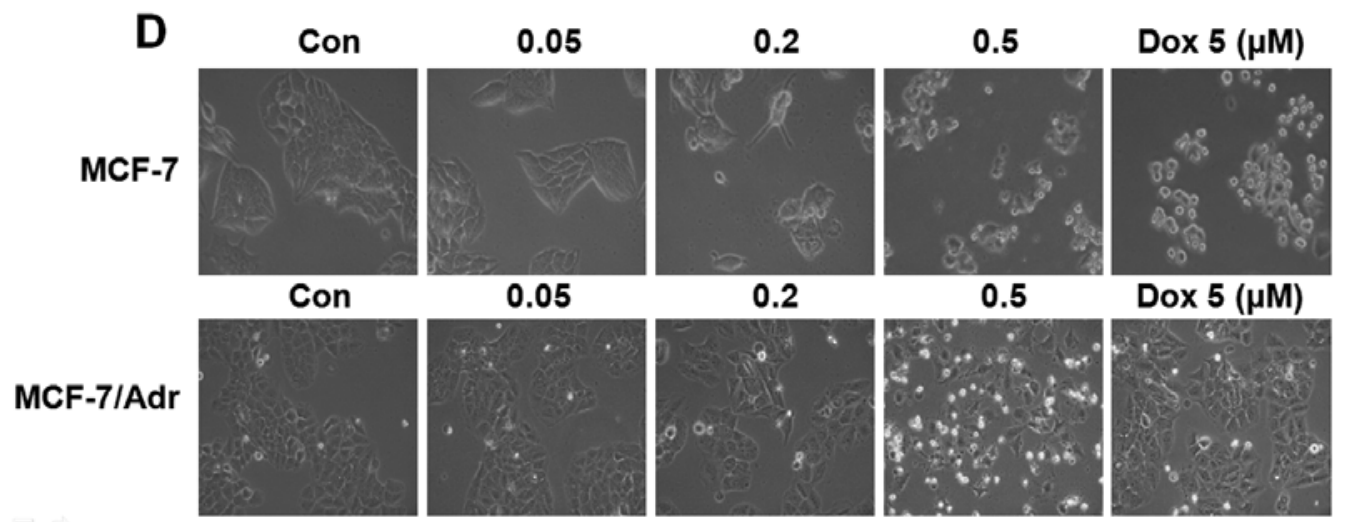

Figure 2. Effects of MHY412 and doxorubicin (Dox) on cell viability measured by MTT assay: MCF-7 cells and MCF-7/Adr cells were treated with MHY412 and DOX at various concentrations (0.05-20 $\mu \mathrm{M})$ for 24 and $48 \mathrm{~h}$, respectively. The viability of the (A) MCF-7 cells and (B) MCF-7/Adr cell was measured with the MTT assay. (C) MCF-7/Adr cells were plated onto 96 -well plates at 1x105 cells/well, followed by treatment with various concentrations of MHY412 and Dox $(5 \mu \mathrm{M})$ and incubation at $37^{\circ} \mathrm{C}$ for 12 and $24 \mathrm{~h}$, respectively. Then, viable cells were determined by counting the cells in a cell counter with a microscope. Results are expressed as the mean \pm SEM of triplicate independent experiments. (D) Morphological changes were observed after MHY412 and Dox treatment. The cells were treated for $48 \mathrm{~h}$ with the indicated concentrations of MHY412 and Dox. Magnification, x200.

sub-G1 phase arrest was significantly increased in MCF-7/Adr cells treated with $0.2 \mu \mathrm{M}$ MHY412 (Fig. 3B). The percentage of cells in the sub-G1 phase, which is indicative of apoptotic cell death, significantly increased after treatment with MHY412 in MCF-7 cells $(0.5 \mu \mathrm{M}, 28.84 \%)$ and MCF-7/Adr cells $(0.2 \mu \mathrm{M}$, 23.42\%) as compared with control (Fig. 4A). In addition, we examined the expression of cyclin D1, cyclin E, CDK2 and p21 levels using western blot analysis, because these proteins are closely associated with the cell cycle checkpoints. MHY412 significantly decreased the expression of cyclin D1 and CDK2 in MCF-7 cells, whereas the p21 expression level increased at a high concentration of MHY412 (Fig. 3C). Dox did not affect the expression level of p21 in MCF-7 and MCF-7/Adr cells. However, MHY412 significantly decreased cyclin E and CDK2 levels in MCF-7/Adr cells, but expression of p21 level was increased in MCF-7/Adr cells (Fig. 3D).

MHY412 induces apoptotic cell death. To understand the mechanism underlying the cytotoxic effect of MHY412 on MCF-7/Adr cells, we assessed apoptotic cell death using Annexin V-FITC assay,DAPI staining and western blot analysis. Generally, Annexin V/PI staining can be used to differentiate cells in the early or late stage of apoptosis as well as necrotic cells. MHY412 at high concentration $(0.2 \mu \mathrm{M})$ significantly increased the population of MCF-7/Adr cells in the late stage of apoptosis, 6.2 and $28.8 \%$, and the percentage of apoptosis was $23.4 \%$ when MCF-7 cells were treated with $0.5 \mu \mathrm{M}$ of MHY412 (Fig. 4A). In contrast, Dox did not induce apoptotic cell death in MCF-7/Adr cells because these cells show an efflux of Dox; further, broadband fluorescence emitted by Dox interferes with the Annexin V/PI staining assay. DAPI staining was used to confirm the effect of MHY412 on apoptosis in MCF-7 and MCF-7/Adr cell lines. Compared to control culture, MHY412 induced a number of apoptotic nuclei (condensed or fragmented chromatin), which showed enhanced fluorescence with DAPI staining (Fig. 4B). For determination of the apoptosis pathway, we measured the expression level of apoptosis-related proteins using western blot analysis. Treatment with MHY412 $(0.5 \mu \mathrm{M})$ and Dox $(5 \mu \mathrm{M})$ significantly increased the cleavage of PARP, upregulated Bax expression, and increased cytochrome $c$ release, while the expression of Bcl-2 was decreased in MCF-7 and MCF-7/Adr cells at high concentration of MHY412 (Fig. 5A and $\mathrm{B})$.

MHY412 decreases expression of P-gp, BCRP and ER in $M C F-7 / A d r$ cells. Western blot analysis and RT-PCR were 

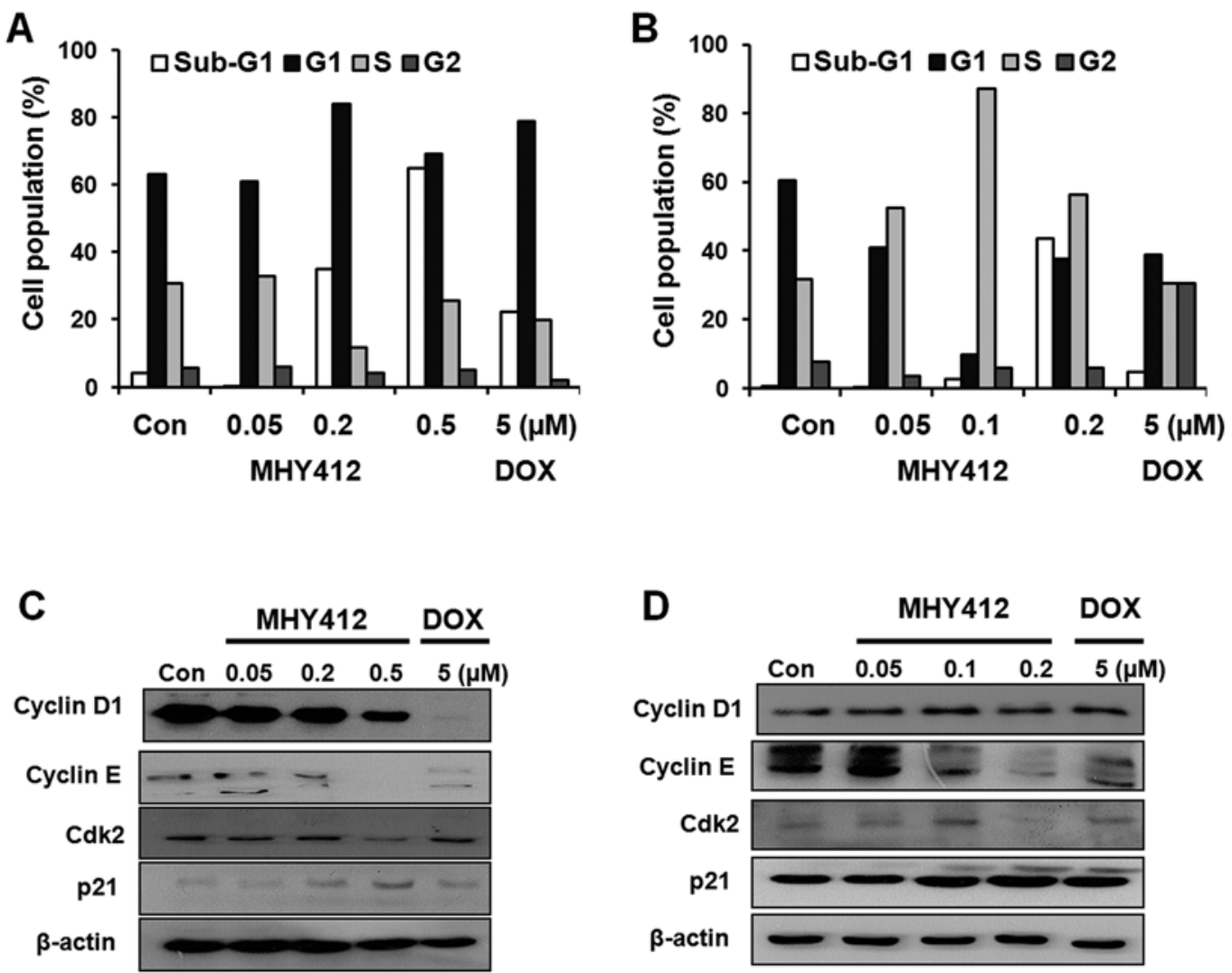

Figure 3. Effects of MHY412 and doxorubicin (Dox) on cell cycle distribution and expression of cell cycle regulatory proteins. (A) MCF-7 and (B) MCF-7/Adr cells were treated for $48 \mathrm{~h}$ with MHY412 and Dox at the indicated concentrations and then cells were stained with propidium iodide (PI) and subjected to flow cytometry analysis to determine their distribution in each phase of the cell cycle. At a concentration of $0.05 \mu \mathrm{M}$ of MHY412, S phase arrest without induction of sub-G1 phase was observed in both cell lines, but at 0.2 and $0.5 \mu \mathrm{M}$, a significant increase in the number of cells in the sub-G1 phases was observed. (C) MCF-7 and (D) MCF-7/Adr cells were treated with MHY412 and Dox at the indicated concentrations for $48 \mathrm{~h}$ and then the level of protein expression was detected using western blot analysis. The cells were homogenized and the proteins were isolated. Aliquots of proteins were immunoblotted with specific primary antibodies against cyclin D1, cyclin E, CDK2 and p21. Equal loading and transfer were verified by re-probing the membranes with $\beta$-actin antibody.

used to determine the expression levels of P-gp and BCRP in human breast cancer cell lines. MCF-7/Adr cells showed a marked upregulation of P-gp gene expression (Fig. 6). After 48-h incubation with MHY412 (0.05, 0.1 and $0.2 \mu \mathrm{M})$, the expression levels of P-gp decreased in a concentrationdependent manner. These results indicated that MHY412 downregulated the expression level of P-gp. Similarly, MHY412 decreased the BCRP expression in a concentrationdependent manner. However, Dox treatment for $48 \mathrm{~h}$ did not affect the expression levels of P-gp and BCRP that regulate apoptosis in MDR breast cancer cells. Compared to control cells, cells treated with $5 \mu \mathrm{M}$ Dox for $48 \mathrm{~h}$ showed no change in the expression level of ABC proteins (Fig. 6B). MHY412 at a low concentration $(0.05$ and $0.2 \mu \mathrm{M})$ had no effect on the expression level of ER $\alpha$ protein in ER-positive MCF-7 cells after $48 \mathrm{~h}$, but at high concentration of MHY412 $(0.5 \mu \mathrm{M})$ showed a significant decrease in the ER $\alpha$ protein levels in MCF-7 cells (Fig. 6C). However, MHY412 and Dox did not change ER $\alpha$ protein expression (Fig. 6D).

Effect of MHY412 on tumor growth in the xenograft model. To confirm the antitumor effects of MHY412 on MCF-7/ Adr cells, we used a tumor xenograft model developed using athymic BALB/c nude mice. MHY412 $(5 \mathrm{mg} / \mathrm{kg}$, i.p., once a week) and Dox (5 mg/kg, i.p., once a week) were injected to tumor-bearing mice inoculated with MCF-7/Adr cells. Compared to the control group, the MHY412-treated group of mice showed a significant delay of $25 \%$ in the tumor growth, whereas Dox showed a minimal inhibitory effect on tumor growth of $8 \%$ compared to that in the control group (Fig. 7A). The final tumor size in mice treated with MHY412 was approximately 50\% lower than that in control mice (Fig. 7B). These data clearly indicate that MHY412 suppresses the growth of Dox-resistant human breast cancer cells. In addition, the antitumor effects of MHY412 in an in vivo model were investigated by examining the expression of PCNA, a cell proliferation marker, by immunohistochemical analysis of paraffin-embedded tumor sections. The histological changes between the drug-treated and control group were examined using $\mathrm{H} \& \mathrm{E}$ staining in paraffinembedded tumor sections (Fig. 7C). The percentage of cancer cells with a positive stained nucleus for PCNA was much lower in MHY412-treated group than in control and Dox-treated groups (Fig. 7D). These results indicate that the MHY412 exerts its anticancer effect by inhibiting cancer cell proliferation in vitro and in vivo. The antitumor effect of MHY412 was studied through the induction of apoptosis in breast cancer cells in vitro. Next, we examined apoptotic cell death using a TUNEL assay using paraffin-embedded tumor sections. Compared to the vehicle-treated control, MHY412 


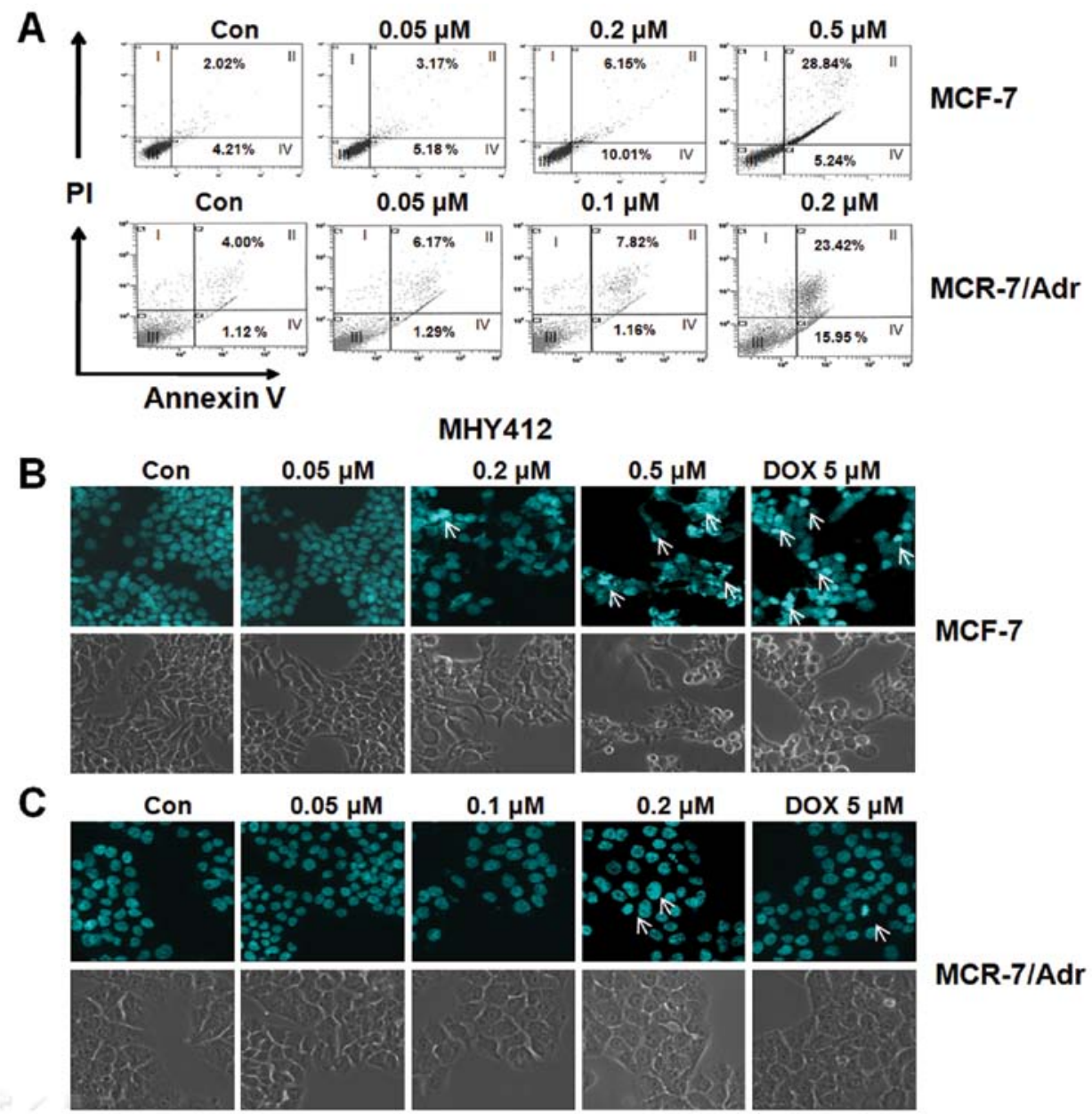

Figure 4. Effects of MHY412 and doxorubicin (Dox) on apoptotic cell death in MCF-7 and MCF-7/Adr cells. (A) MHY412-induced apoptosis was examined using Annexin V/PI binding assay. Both types of cells were treated with MHY412 for $48 \mathrm{~h}$ at different concentrations as indicated. Representative flow cytometry scatter plots II and III indicate the percentage of cells in the early and late phase of apoptosis after MHY412 treatment. (B) MCF-7 and (C) MCF-7/Adr cells were treated with MHY412 and Dox for $48 \mathrm{~h}$ with the indicated concentrations, followed by fixation and 4',6-diamidino-2-phenylindole (DAPI) staining. Upper images were observed in bright field, whereas lower image shows corresponding DAPI staining in a fluorescence microscope. Apoptotic cells are marked by arrows.

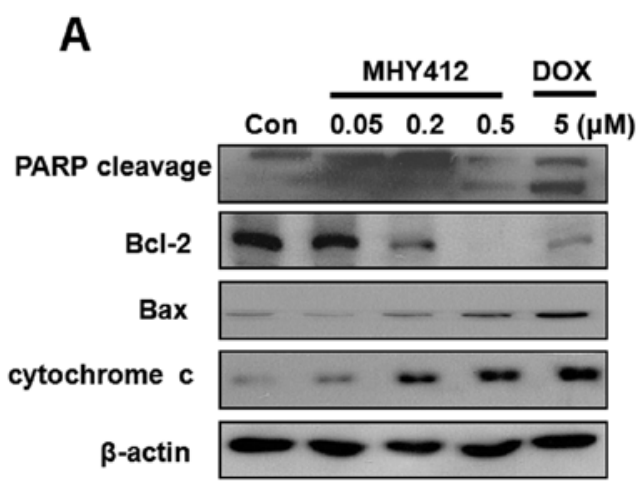

B

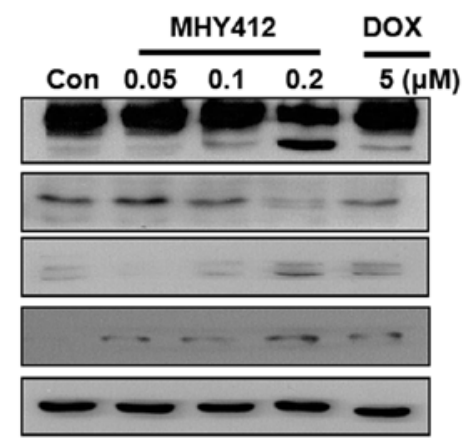

Figure 5. Effects of MHY412 on apoptotic cell death pathways. (A) MCF-7 and (B) MCF-7/Adr cells were treated with MHY412 for $48 \mathrm{~h}$ and nuclear proteins were used to evaluate poly-ADP ribose polymerase (PARP) cleavage. MCF-7 cells were treated with MHY412 for $48 \mathrm{~h}$ and the cytosolic protein was isolated to measure Bax, $\mathrm{Bcl}-2$ and cytochrome $c$ levels. The protein levels were normalized by a comparison with the levels of $\beta$-actin.

showed a 1.5 -fold increase in the TUNEL-positive apoptotic cell population (Fig. 7E). These results show that the in vitro effect of MHY412 on the inhibition of cell proliferation is associated with the anticancer activity of MHY412 in vivo.

\section{Discussion}

Novel anthracene derivatives have been used as useful chemotherapeutic drugs for the treatment of various cancers and thus 

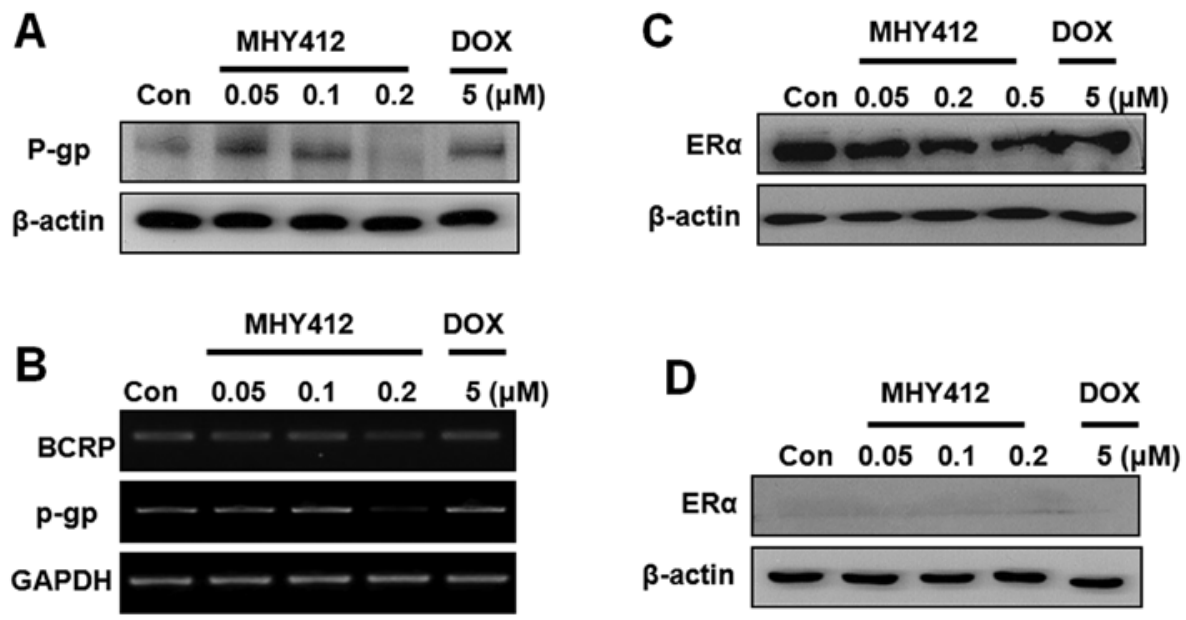

Figure 6. Effects of MHY412 and doxorubicin (Dox) on the levels of P-glycoprotein (P-gp), breast cancer resistance protein (BCRP) and ER $\alpha$ protein expression in breast cancer cell lines. MCF-7/Adr cells were treated with MHY412 $(0.05,0.1$ and $0.2 \mu \mathrm{M})$ and Dox $(0.5 \mu \mathrm{M})$ at the indicated concentrations for $48 \mathrm{~h}$. (A) Effect of MHY412 on P-gp expression levels in MCF-7/Adr cells. The MCF-7/Adr cells were treated with MHY412 at the indicated concentrations for $48 \mathrm{~h}$. Total cell lysates were prepared and the proteins were subjected to SDS-PAGE followed by western blot analysis. The control cells were treated with the vehicle alone. Representative bands from three independent experiments are shown. (B) The mRNA levels of BCRP and P-gp were measured in MCF-7/Adr cells treated with MHY412. Total RNA was isolated and RT-PCR was performed using the specific primers described in Materials and methods. GAPDH was used as the housekeeping control gene. (C and D) MCF-7 and MCF-7/Adr cells were treated with MHY412 for 48 h, and western blot analysis was performed to detect the ER $\alpha$ expression. The protein level was normalized by comparing with the levels of $\beta$-actin.
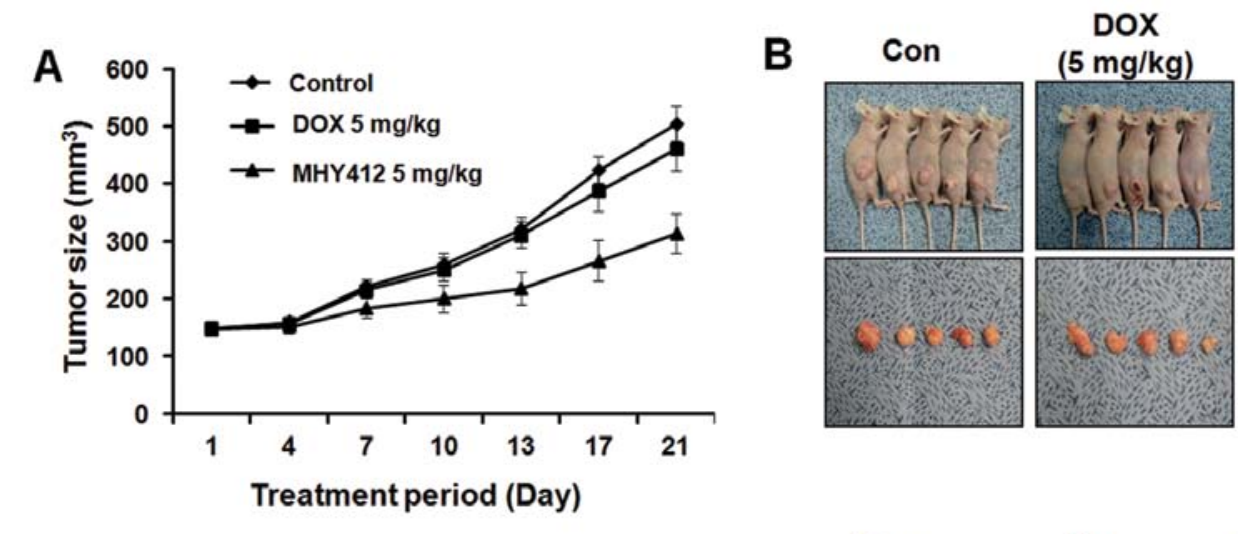

MHY412
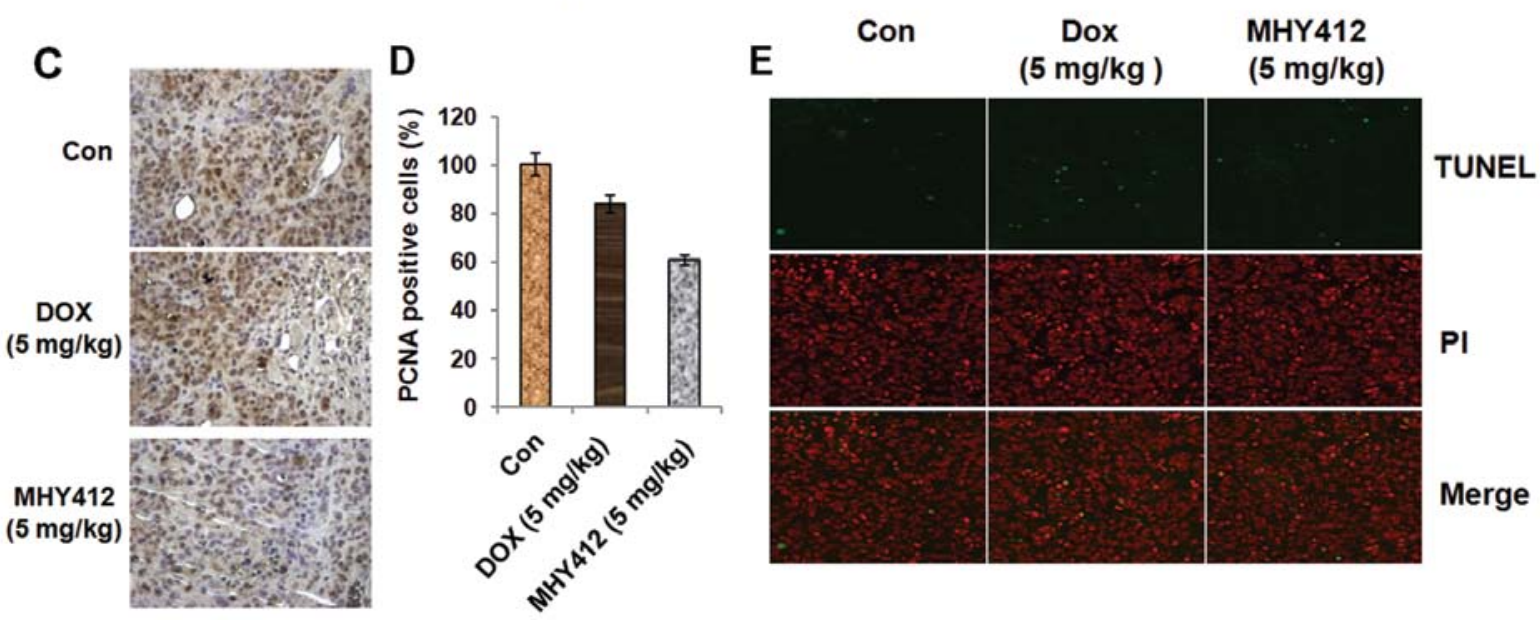

Figure 7. Effect of MHY412 on the growth of tumor-bearing nude mice inoculated with MCF-7/Adr cells. (A) Cells (1.5x107) were injected subcutaneously into the flanks of nude mice. When the tumors were palpable, mice were grouped randomly into 3 groups with 4 mice in each group. Then, the mice were treated with control vehicle, MHY412 $(5 \mathrm{mg} / \mathrm{kg})$, or Dox $(5 \mathrm{mg} / \mathrm{kg})$ by i.p. injection (once a week). Tumor growth was monitored weekly by measuring the tumor size. ${ }^{*} \mathrm{P}<0.05 ;{ }^{* * * *} \mathrm{P}<0.001$. (B) Tumors were isolated from the mice at the end of treatment. Photographs of representative tumors are shown. Bar, $1 \mathrm{~cm}$. (C) The weight of each harvested tumor was measured and plotted. Treatment with MHY412 significantly decreased the size of the tumors. ${ }^{*} \mathrm{P}<0.05$. (D) Tumor tissues were fixed using formaldehyde and embedded in paraffin. Then, tissue sections were stained with the anti-proliferating cell nuclear antigen (PCNA) antibody. Bar, $50 \mu \mathrm{m}$. (E) The tumors were fixed in 10\% formalin and embedded in paraffin. Terminal deoxynucleotidyl transferasemediated dUDP nick-end labeling (TUNEL) expression was examined in tissue sections treated with vehicle, MHY412 and Dox. The number of apoptotic events was counted in 10 random fields using confocal laser scanning microscopy (Olympus FV10i, Tokyo Inc., Japan) at x400 magnification and that number was divided by the total number of cells per field. 
numerous drugs have been synthesized and pharmacological studies to determine their anticancer mechanism have been performed. In this study, we examined the inhibitory effect of a novel anthracene derivative MHY412 on the growth of breast cancer cells in vitro and in vivo using tumor xenograft models. Our data suggest that MHY412 is an effective anticancer agent for Dox-resistant breast cancer cells. The overall anticancer activity of MHY412 may be the result of the apoptotic cell death pathway.

Several lines of evidence indicate that apoptotic cell death plays an important role in the molecular mechanism of anticancer drugs (23). To explore the mechanism responsible for the antiproliferative effect of MHY412, we examined the mechanism of apoptosis and cell cycle distribution of MCF-7/ Adr cells. Flow cytometry analysis revealed that MHY412 markedly induced apoptosis and $\mathrm{S}$ phase cell cycle arrest with a decrease in G0/G1 phase in MCF-7 and MCF-7/Adr cells. These effects were similar to those of mitoxantrone, an anthraquinone derivative; the exact downstream mechanism of apoptotic cell deaths induced by MHY412 was the release of cytochrome $c$ into the cytoplasm, upregulation of the proapoptotic protein Bax, downregulation of the anti-apoptotic protein Bcl-2 and PARP cleavage through the intrinsic pathway. These results were confirmed by Annexin V-FITC binding, DNA fragmentation assay and DAPI staining. In particular, the sensitivity of MHY412 on apoptotic cell death is dependent on the cell type. The rate of MHY412-induced apoptosis was higher in MCF-7/Adr cells than in MCF-7 cells because the level of $\mathrm{Bcl}-2$, an anti-apoptotic factor of cancer cells, is much higher in ER-positive MCF-7 cells than in ER-negative MCF-7/Adr cells (18). On the basis of this observation, we determined that $\mathrm{Bcl}-2$ plays an important role in the anticancer activity of MHY412 in MCF-7/Adr cells. Our data indicated that MHY412 significantly decreased the expression of $\mathrm{Bcl}-2$ and $\mathrm{ER} \alpha$. Estrogen promotes resistance to chemotherapeutic drugs by increasing the expression of the Bcl-2 in human breast cancer cell lines (24).

Further studies are required to characterize the molecular pathways underlying MHY412-induced cell cycle arrest in breast cancer cell lines. In the present study, MHY412 at a low concentration induced $\mathrm{S}$ phase arrest in both types of cell lines without changing the levels of the cell cycle regulatory proteins that can play an important role in preventing or recovering cancer cells by prolonging or inhibiting $\mathrm{S}$ phase due to the process of new DNA synthesis occuring during $\mathrm{S}$ phase and thus recovery of cancer cells by various types of tumor suppressor gene requires a longer time (25). In contrast, MHY412 at high concentrations induced S phase and sub-G1 phase arrest and downregulated cyclin E expression in MCF-7/ Adr cells. This result was similar to that reported previously (26). In the case of MCF-7 cells, G1 and sub-G1 phase arrest was observed via downregulation of cyclin D1 and ER $\alpha$ expression in a concentration-dependent manner.

Cyclin D1 plays an important role in cell proliferation (27) and it is mainly overexpressed in the well-differentiated type of invasive breast cancer, and it gives a strong response with ER positivity (19). Up to $50 \%$ of breast cancers overexpress cyclin D1 (28). Cyclin D1 expression is correlated with ER $\alpha$ for well-differentiated tumors, and cyclin D1 overexpression is observed in $79 \%$ of ER-positive tumors and $45 \%$ of ER-negative tumors (29). Cyclin D1 and ER $\alpha$ are related with each other, and together they play an important role in the cell cycle progression from $\mathrm{G} 1$ phase to $\mathrm{S}$ phase. p21 is a kind of cell cycle regulatory protein that inhibits cell cycle progression by interfering with the cell cycle progression from $\mathrm{G} 1$ phase to $\mathrm{S}$ phase $(30,31)$. In the present study, MHY412 induced G1 phase arrest in MCF-7 cells by upregulating the $\mathrm{p} 21$ protein expression. In addition, this cell cycle data indicated that MHY412 increased sub-G1 phase arrest, but no significant change was observed at very low concentrations of MHY412.

Inducing cell death or inhibiting the growth of MCF-7/Adr is very difficult despite using an anticancer agent although the drug easily enters the MCF-7/Adr cells, and induction of apoptotic cell death or cell cycle arrest is difficult because P-gp present in the membranes of MCF-7/Adr cells inhibits apoptosis by inhibiting caspase activation and cytochrome $c$ release from the mitochondria (6). In addition, several antitumor agents cannot inhibit cell cycle progression because most of the resistant cells do not undergo apoptosis via the ER pathway (18). Many anthracene derivatives have potent antitumor activity and are extensively used as anticancer agents $(32,33)$. However, their clinical use is frequently limited by the emergence of MDR in cancer cells. Therefore, new agents with the ability to overcome MDR are required for cancer treatment. MHY412 exhibited potent anticancer activity in both Dox-resistant MCF-7/Adr and MCF-7 cell lines. The mechanism by which MHY412 induced apoptosis in MCF-7/Adr cells was inhibition of the expression of P-gp at high concentration $(0.2 \mu \mathrm{M})$, but at low concentrations $(0.05$ and $0.1 \mu \mathrm{M}), \mathrm{MCF}-7 / \mathrm{Adr}$ cells showed no change in P-gp expression and apoptotic cell death. Our data suggest that MHY412 was neither a substrate nor an inhibitor of P-gp and could overcome apoptotic resistance via upregulation of p21 protein and downregulation of $\mathrm{Bcl}-2$ protein. In addition, MHY412 induced apoptosis in MCF-7/Adr cells and decreased the number of cells in G0/G1 phase. Moreover, increases in the release of cytochrome $c$ and PARP cleavage were also observed. Importantly, MHY412 was $25 \%$ effective in inhibiting tumor growth in nude mice inoculated with $\mathrm{MCF}-7 / \mathrm{Adr}$ cells using a tumor xenograft model.

In conclusion, we found that MHY412 induced apoptotic cell death through cell cycle arrest, downregulation of $\mathrm{P}$-gp expression and increase in the release of cytochrome $c$ from the mitochondria to cytoplasm in MCF-7/Adr cells. Simultaneous activation of both the mitochondrial pathway and P-gp-mediated pathway in MCF-7/Adr cells might explain why cell death was more rapidly induced in MDR cells. Collectively, our results suggest that MHY412 induces apoptosis via a Bcl-2/Bax-mediated pathway in MCF-7/Adr cells. In addition, P-gp was involved in controlling MHY412-mediated apoptosis. Furthermore, MHY412 showed more potent antitumor activity against MCF-7/Adr cells than MCF-7 cells. On the basis of our results, we suggest that MHY412 is a novel anticancer agent for treatment of human breast cancer and its anticancer activity is much higher than that of Dox.

\section{Acknowledgements}

This study was supported by National Research Foundation of Korea (NRF) grants funded by the Korea Government (nos. 2010-0023750 and 2011-0030652). 


\section{References}

1. American Cancer Society: Breast Cancer Facts and Figures 2011-2012. ACS, Atlanta, GA, 2012.

2. DeSantis C, Siegel R, Bandi P, et al: Breast cancer statistics, 2011. CA Cancer J Clin 61: 409-418, 2011.

3. Mariani G: New developments in the treatment of metastatic breast cancer: from chemotherapy to biological therapy. Ann Oncology 16 (Suppl 2): 191-194, 2005.

4. Ambudkar SV, Sarfaty CK, Sauna ZE, et al: P-glycoprotein: from genomics to mechanism. Oncogene 22: 7468-7485, 2003.

5. Larsen AK, Escargueil AE and Skladanowski A: Resistance mechanisms associated with altered intracellular distribution of anticancer agents. Pharmacol Ther 85: 217-229, 2000.

6. Molinari A, Calcabrini A, Meschini S, et al: Subcellular detection and localization of the drug transporter P-glycoprotein in cultured tumor cells. Curr Protein Pept Sci 3: 653-670, 2002.

7. Kars MD, Işeri OD and Gündüz U: A microarray based expression profiling of paclitaxel and vincristine resistant MCF-7 cells. Eur J Pharmacol 657: 4-9, 2011.

8. Xu JW, Li QQ, Tao LL, et al: Involvement of EGFR in the promotion of malignant properties in multidrug resistant breast cancer cells. Int J Oncol 39: 1501-1509, 2011.

9. Tainton KM, Smyth MJ, Jackson JT, et al: Mutational analysis of P-glycoprotein: suppression of caspase activation in the absence of ATP-dependent drug efflux. Cell Death Differ 11: 1028-1037, 2004.

10. Howell A, DeFriend D, Robertson JFR, et al: Response to a specific antiestrogen (ICI 182,780) in tamoxifen-resistant breast cancer. Lancet 345: 29-30, 1995.

11. Howell A, Howell SJ and Evans DG: New approaches to the endocrine prevention and treatment of breast cancer. Cancer Chemother Pharmacol 52: S39-S44, 2003.

12. Labbozzetta M, Notarbartolo M, Poma P, et al: Curcumin as a possible lead compound against hormone-independent, multidrug-resistant breast cancer. Ann NY Acad Sci 1155: 278-283, 2009.

13. Sui M, Huang Y, Park BH, et al: Estrogen receptor $\alpha$ mediates breast cancer cell resistance to paclitaxel through inhibition of apoptotic cell death. Cancer Res 67: 5337-5344, 2007.

14. Smith L, Watson BM, O'Kane SL, et al: The analysis of doxorubicin resistance in human breast cancer cells using antibody microarrays. Mol Cancer Ther 5: 2115-2120, 2006.

15. Sharpe JC, Arnoult D and Youle RJ: Control of mitochondrial permeability by Bcl-2 family members. Biochim Biophys Acta 1644: 107-113, 2004.

16. Zamzami N, Brenner C, Marzo I, et al: Subcellular and submitochondrial mode of action of Bcl-2-like oncoproteins. Oncogene 16: 2265-2282, 1998.

17. Kowaltowski AJ, Cosso RG, Campos CB, et al: Effect of Bcl-2 overexpression on mitochondrial structure and function. J Biol Chem 277: 42802-42807, 2002.

18. Calcabrini A, Martínez JM, González L, et al: Inhibition of proliferation and induction of apoptosis in human breast cancer cells by lauryl gallate. Carcinogenesis 27: 1699-1712, 2006.
19. Tarasiuk J, Majewska E, Seksek O, et al: The role of structural factors in the kinetics of cellular uptake of pyrazoloacridines and pyrazolopyrimidoacridines: Implications for overcoming multidrug resistance towards leukaemia K562/DOX cells. Biochem Pharmacol 68: 1815-1823, 2004.

20. Pourpak A, Landowski TH and Dorr RT: Ethonafide-induced cytotoxicity is mediated by topoisomerase II inhibition in prostate cancer cells. J Pharmacol Exp Ther 321: 1109-1117, 2007.

21. Xie SQ, Hu GQ, Zhang ZQ, et al: Anti-tumour effects of HL-37, a novel anthracene derivative, in-vivo and in-vitro. J Pharm Pharmacol 60: 213-219, 2008.

22. Zhang G, Fang L, Zhu L, et al: Syntheses and biological activities of 3'-azido disaccharide analogues of daunorubicin against drug-resistant leukemia. J Med Chem 49: 1792-1799, 2006.

23. Kim R: Recent advances in understanding the cell death pathways activated by anticancer therapy. Cancer 103: 1551-1560, 2005

24. Teixeira C, Reed JC and Pratt MA: Estrogen promotes chemotherapeutic drug resistance by a mechanism involving $\mathrm{Bcl}-2$ proto-oncogene expression in human breast cancer cells. Cancer Res 55: 3920-3907, 1995.

25. Lu M, Lopez RM, Nakajo S, et al: Expression of estrogen receptor $\alpha$, retinoic acid receptor a and cellular retinoic acid binding protein II genes is coordinately regulated in human breast cancer cells line. Oncogene 24: 4362-4369, 2005.

26. Alle KM, Henshall SM, Field AS, et al: Cyclin D1 protein is overexpressed in hyperplasia and intraductal carcinoma of the breast. Clin Cancer Res 4: 847-854, 1998.

27. Van Diest PJ, Michalides RJ, Jannink L, et al: Cyclin D1 expression in invasive breast cancer. Correlations and prognostic value. Am J Pathol 150: 705-711, 1997.

28. Gillett C, Fantl V,Smith R, et al: Amplification and overexpression of cyclin D1 in breast cancer detected by immunohistochemical staining. Cancer Res 54: 1812-1817, 1994.

29. Naidu R, Wahab NA, Yadav MM, et al: Expression and amplification of cyclin D1 in primary breast carcinomas: relationship with histopathological types and clinico-pathological parameters. Oncol Rep 9: 409-416, 2002.

30. Lavelle D, DeSimone J, Hankewych M, et al: Decitabine induces cell cycle arrest at the G1 phase via p21WAF1 and the $\mathrm{G} 2 / \mathrm{M}$ phase via the p38 MAP kinase pathway. Leuk Res 27: 999-1007, 2003.

31. Sandor V, Senderowicz A, Mertins S, et al: p21-dependent G1 arrest with downregulation of cyclin D1 and upregulation of cyclin E by the histone deacetylase inhibitor FR901228. Br J Cancer 83: 817-825, 2000.

32. Marqués-Gallego P, Contaldi S, den Dulk H, et al: Relevance of the leaving group for antitumor activity of new platinum(II) compounds containing anthracene derivatives as a carrier ligand. J Inorg Biochem 103: 1602-1608, 2009.

33. Nazarov AA, Risse J, Ang WH, et al: Anthracene-tethered ruthenium(II) arene complexes as tools to visualize the cellular localization of putative organometallic anticancer compounds. Inorg Chem 51: 3633-33639, 2012. 